\title{
MONTEIRO LOBATO ESCREVE DE VOLTA PARA FÁBULAS EUROPEIAS: A EMERGÊNCIA DE UMA LITERATURA INFANTIL QUE VISA A RECUPERAR IDENTIDADES ALTERNATIVAS
}

\author{
Sandra Helena Borges \\ Mestre em Letras pela Universidade Federal de Uberlândia (UFU) \\ borgesandra1@gmail.com
}

\section{RESUMO}

O tema deste estudo é a recuperação de identidades alternativas. Dessa forma, objetiva-se investigar, por meio de uma abordagem pós-colonial, os campos de estratégias de contradiscursividade dentro do contradiscurso da fábula $A$ cigarra e as formigas, de Monteiro Lobato, que foi publicada em 1921. A abordagem póscolonial repensa as profundas limitações da noção de universalismo da cultura humana e sustenta que a identidade cultural e a identidade política são construídas por meio de um processo de alteridade. As estratégias de contradiscursividade mapeiam o discurso dominante, leem e expõem suas premissas subjacentes, que são incoerentes ao ponto de vista transcultural do local imperialmente subjetivado. O suporte teórico foi buscado em Bhabha (1998), Tiffin (1987), Ashcroft, Griffiths e Tiffin (2002), Souza (1996), Santos e Menezes (2010), Foucault (1995, 1996), Ashcroft (2001), Bakhtin (2002), Arroyo (2011), Lobato (1972) e Bagno (2006).

Palavras-chave: contradiscurso, Monteiro Lobato, identidade, alteridade.

\begin{abstract}
The theme of this study is the recovery of alternative identities. Thus, the objective is to investigate, through a postcolonial approach, the fields of counter-discursive strategies within the counter-discourse of the fable The cicada and the ants, by Monteiro Lobato, which was published in 1921. The postcolonial approach rethinks the profound limitations of the notion of universalism of human culture, and maintains that cultural identity and political identity are constructed through a process of alterity. Contradiscursivity strategies map the dominant discourse, read and expose its underlying premises, which are inconsistent with the crosscultural view of the imperially subjectivized place. The theoretical support was sought in Bhabha (1998), Tiffin (1987), Ashcroft, Griffiths and Tiffin (2002), Souza (1996), Santos and Menezes (2010), Foucault (1995, 1996), Ashcroft (2002), Arroyo (2011), Lobato (1972) and Bagno (2006).
\end{abstract}

Keywords: counter-discourse, Monteiro Lobato, identity, alterity. 


\title{
Introdução
}

Em correspondência a Godofredo Rangel', datada de 1916, o escritor brasileiro Monteiro Lobato relata suas inquietações literárias, revelando um pensamento progressista:

\begin{abstract}
Ando com várias ideias. Uma: vestir à nacional as velhas fábulas de Esopo e La Fontaine, tudo em prosa e mexendo nas moralidades. Coisa para crianças. Veio-me diante da atenção curiosa com que meus pequenos ouvem as fábulas que Purezinha conta. Guardam-nas de memória e vão recontá-las aos amigos - sem, entretanto, prestarem atenção à moralidade, como é natural. A moralidade nos fica no subconsciente para ir se revelando mais tarde, à medida que progredimos em compreensão. Ora, um fabulário nosso, com bichos daqui em vez dos exóticos, se for feito com arte e talento dará coisa preciosa. As fábulas em português que conheço, em geral traduções de La Fontaine, são pequenas moitas de amora do mato - espinhentas e impenetráveis. Que é que nossas crianças podem ler? Não vejo nada. Fábulas assim seriam um começo da literatura que nos falta. (...). É de tal pobreza e tão besta a nossa literatura infantil, que nada acho para a iniciação de meus filhos [...] (LOBATO, 1972, p. 245).
\end{abstract}

Lobato, em 1921, executa a primeira ideia exposta na correspondência destinada a Godofredo Rangel e, assim, escreve de volta para Esopo e La Fontaine. Não simplesmente "escreve de volta" para os textos canônicos europeus, mas para todos os campos discursivos dentro dos quais tais textos operam e continuam a operar em mundos pós-coloniais. Nesse sentido, os dois textos lobatianos que compõem a fábula $A$ cigarra e as formigas não são apenas continuações ou adaptações das fábulas europeias, mas interrogações dos seus discursos coloniais e de suas estratégias discursivas.

Ao desafiar a noção de universalidade das fábulas de Esopo e La Fontaine, Monteiro Lobato engaja-se no contradiscurso. A noção de universalidade da literatura 
europeia (cânone literário) envolve relações históricas de poder entre o Primeiro e o Terceiro Mundo, hoje conhecidos por Norte e Sul Global e fomenta a centralidade do discurso dominante, consagrando, com isso, os valores de uma cultura particular como axiomática.

O estabelecimento da universalidade da literatura europeia envolve, portanto, a fixação de modelos ou regras do centro imperial, "com suas ironias históricas, suas temporalidades disjuntivas, seus paradoxos do progresso, sua aporiaii da representação" (BHABHA, 1998, p. 244).

De acordo com Slemon (1988, apud ASHCROFT, GRIFFITHS, TIFFIN, 2002), o termo contradiscurso, isto é, o discurso que corre "contra" o cânone estabelecido e que privilegia o uso e o sincretismo foi apropriado, pela crítica pós-colonial, de Richard Terdiman. Para o professor de Literatura e História da Consciência na Universidade da Califórnia, em Santa Cruz, o signo obtém seu significado em conflito e contradição; nesse sentido, nenhum discurso é um monólogo, pois pressupõe sempre um horizonte de competição. Portanto, concordando com Foucault (1996), nenhum discurso, para Terdiman, é contínuo e totalitário, nenhum discurso é imune a dúvidas e reflexividade. São as rupturas que se abrem dentro dele que permitem, conforme ressalta Ashcroft (1991), formas de resistência.

Por meio de uma abordagem pós-colonial, este trabalho objetiva investigar os 'campos' de estratégias de contradiscursividade dentro do contradiscurso da fábula $A$ cigarra e as formigas, de Monteiro Lobato (2012) ${ }^{\text {iii }}$. Esse tipo de investigação vem sendo feita na crítica pós-colonial por Tiffin (1987). O conceito de 'campos', que a pesquisadora busca no estudioso canadense Dennis Lee, que analisa os efeitos do colonialismo na população nativa original, e o adapta, invoca a ideia de uma força invisível, mas definível 
e realça a ideia de que as estratégias de contradiscursividade são de muitas formas em diferentes culturas.

As estratégias de contradiscursividade, segundo Tiffin (1987, p. 23), envolvem "um mapeamento do discurso dominante, uma leitura e exposição de suas premissas subjacentes, e a desconexão desses pressupostos do ponto de vista transcultural do local imperialmente subjetivado"iv ${ }^{\text {iv }}$ Portanto, essas estratégias permitem negociações de poderes da diferença cultural - "processo da enunciação da cultura como 'conhecível', legítimo, adequado à construção de sistemas de identificação cultural" (BHABHA, 1998, p. 63, grifo do autor) - em vários lugares trans-históricos.

A abordagem pós-colonial, para Bhabha (1998), dialoga com as "epistemologias do Sul”v na construção do saber e

nos força a repensar as profundas limitações de uma noção 'liberal' consensual e conluiada de comunidade cultural. Ela insiste que a identidade cultural e a identidade política são construídas através de um processo de alteridade. Questões de raça e diferença cultural sobrepõem-se às problemáticas da sexualidade e do gênero e sobredeterminam as alianças sociais de classe e de socialismo democrático (BHABHA, 1998, p. 244-245).

\section{Literaturas pós-coloniais}

As literaturas pós-coloniais surgiram, segundo Ashcroft, Griffiths e Tiffin (2002, p. 02), "a partir da experiência de colonização e afirmaram-se colocando em primeiro plano a tensão com o poder imperial, e enfatizando suas diferenças em relação a pressupostos do centro imperial”vi. 
Entretanto, segundo Bhabha (1998), algumas literaturas pós-coloniais surgiram dos discursos de grupos marginalizados do Norte Global (antigo Primeiro Mundo), pois o imperialismo e suas influências é um fenômeno mundial. Sendo assim, de modo geral, são pós-coloniais as literaturas que oferecem "resistência à normatização do processo colonial, desmascarando e desmistificando a autoridade colonizadora europeia e seus valores excluidores, delineando assim, uma estratégia descolonizante que visa à recuperação de identidades alternativas" (SOUZA, 1996, p. 45).

De acordo com Tiffin (1987, p.18), essas literaturas "são constituídas em práticas contradiscursivas ao invés das homólogas; e oferecem os recursos das estratégias de contradiscursividade ao discurso dominante"vii. Essas estratégias, para a pesquisadora, tornam os discursos das literaturas pós-coloniais dinâmicos ou não estáticos, pois não procuram subverter o discurso dominante visando a tomar o seu lugar, mas procuram expô-lo e corroê-lo. O discurso dominante é, segundo Bhabha (1998, p. 239), “o discurso ideológico da modernidade que tenta dar uma 'normalidade' hegemônica ao desenvolvimento irregular e as histórias diferenciadas de nações, raças, comunidades, povos".

Tiffin (1987) salienta que a formação e a consolidação das literaturas pós-coloniais se dão na subversão do discurso colonial (o discurso dominante), ou seja, na resposta ao centro desse discurso. Essa resposta, para a pesquisadora australiana, parte de uma tomada de posição nacionalista e do questionamento da visão europeia e eurocêntrica do mundo, que desafia a sistematização de polos antagônicos (dominador-dominado) para regulamentar a realidade. As literaturas pós-coloniais revelam, portanto, as fronteiras do discurso colonial, permitindo a transgressão desses limites. 
Desse modo, as literaturas pós-coloniais são preocupadas com a força da escrita, sua metaforicidade e seu discurso e, com isso, são profundamente situadas cultural e politicamente (TIFFIN, 1987). Ou seja, essas literaturas tentam apreender e assumir a responsabilidade pelos passados não ditos, não representados. Elas questionam a relação entre a cultura e o imperialismo para a compreensão da política e da cultura na era da descolonização.

\section{Fábula A cigarra e as formigas, de Monteiro Lobato}

A partir do século XVIII as fábulas do poeta-fabulista francês Jean de La Fontaine, como composições literárias, começaram a ser largamente admiradas e imitadas dentro e fora da Europa. Ou seja, devido às modificações de estrutura econômica e social e suas repercussões no próprio sistema de relações sociais, que favoreceram a formação de um novo público (o infantil) para escritores (ARROYO, 2011), as fábulas de La Fontaine deram origem a outros atos novos de fala que as retomaram, as transformaram ou falaram delas. Entretanto, segundo Arroyo (2011), algumas fábulas do poeta-fabulista francês retornaram e transformaram as fábulas do escritor da Grécia Antiga Esopo, e dentre as quais está a fábula $A$ cigarra e as formigas.

Desse modo, em 1921, quando Monteiro Lobato retoma e subverte o discurso colonial da fábula A cigarra e a formiga, de La Fontaine ${ }^{\text {viii }}$, para finalidades pós-coloniais, engajando-se, com isso, no contradiscurso, também foi retomado e subvertido o discurso da fábula A cigarra e as formigas, de Esopo. Com isso, Lobato realiza um ponto de vista, pois "a língua é uma opinião plurilíngue concreta sobre o mundo" (BAKHTIN, 2002, p. 
$100)^{\text {ix }}$. O ponto de vista realizado responde, portanto, ao ponto de vista da tradição colonial.

Essa resposta, para Bhabha (1998), revela as fronteiras do ponto de vista equivocado ou reprimido ideologicamente da tradição colonial e, com isso, transgride os seus limites a partir do espaço da alteridade, tornando possível compreender a ambivalência produtiva desse ponto de vista. A "alteridade" na fábula A cigarra e a formiga, de La Fontaine, "é ao mesmo tempo um objeto de desejo e escárnio" (BHABHA, 1998, p. 106), uma articulação da diferença contida dentro do seu regime de verdade:

\section{A cigarra e as formigas}

\section{I-A formiga boa}

Houve uma jovem cigarra que tinha o costume de chiar ao pé dum formigueiro. Só parava quando cansadinha; e seu divertimento então era observar as formigas na eterna faina de abastecer as tulhas. Mas o bom tempo afinal passou e vieram as chuvas. Os animais todos, arrepiados, passavam o dia cochilando nas tocas. A pobre cigarra, sem abrigo em seu galhinho seco e metida em grandes apuros, deliberou socorrer-se de alguém. Manquitolando, com uma asa a arrastar, lá se dirigiu para o formigueiro. Bateu - tique, tique, tique... Aparece uma formiga, friorenta, embrulhada num xalinho de paina.

- Que quer? - perguntou, examinando a triste mendiga suja de lama e a tossir.

- Venho em busca de um agasalho. O mau tempo não cessa e eu...

A formiga olhou-a de alto a baixo.

- E o que fez durante o bom tempo, que não construiu sua casa?

A pobre cigarra, toda tremendo, respondeu depois de um acesso de tosse:

- Eu cantava, bem sabe...

- Ah! ... exclamou a formiga recordando-se. Era você então quem cantava nessa árvore enquanto nós labutávamos para encher as tulhas?

- Isso mesmo, era eu... 
- Pois entre, amiguinha! Nunca poderemos esquecer as boas horas que sua cantoria nos proporcionou. Aquele chiado nos distraía e aliviava o trabalho. Dizíamos sempre: que felicidade ter como vizinha tão gentil cantora! Entre, amiga, que aqui terá cama e mesa durante todo o mau tempo.

A cigarra entrou, sarou da tosse e voltou a ser a alegre cantora dos dias de sol.

\section{II - A formiga má}

Já houve, entretanto, uma formiga má que não soube compreender a cigarra e com dureza a repeliu de sua porta. Foi isso na Europa, em pleno inverno, quando a neve recobria o mundo com o seu cruel manto de gelo. A cigarra, como de costume, havia cantado sem parar o estio inteiro, e o inverno veio encontrá-la desprovida de tudo, sem casa onde abrigar-se, nem folhinhas que comesse. Desesperada, bateu à porta da formiga e implorou - emprestado, notem! - uns miseráveis restos de comida. Pagaria com juros altos aquela comida de empréstimo, logo que o tempo o permitisse. Mas a formiga era uma usuária sem entranhas. Além disso, invejosa. Como não soubesse cantar, tinha ódio à cigarra por vê-la querida de todos os seres.

- Que fazia você durante o bom tempo?

- Eu... eu cantava!...

- Cantava? Pois dance agora, vagabunda! - e fechou-lhe a porta

no

nariz.

Resultado: a cigarra ali morreu estanguidinha; e quando voltou a primavera o mundo apresentava um aspecto mais triste. Ë que faltava na música do mundo o som estridente daquela cigarra morta por causa da avareza da formiga. Mas se a usuária morresse, quem daria pela falta dela?

\section{Os artistas - poetas, pintores e músicos - são as cigarras da humanidade.}

- Esta fábula está errada! - gritou Narizinho. -Vovó nos leu aquele livro de Maertelinck sobre a vida das formigas - e lá a gente vê que as formigas são os únicos insetos caridosos que existem. Formiga má como essa nunca houve.

Dona Benta explicou que as fábulas não eram lições de História Natural, mas de Moral.

- É tanto assim - disse ela - que nas fábulas os animais falam e na realidade eles não falam.

- Isso não - protestou Emília - não há animalzinho, bicho, formiga ou pulga que não fale. Nós é que não entendemos as linguinhas deles. 
Dona Benta aceitou a objeção e disse:

- Mas nas fábulas os animais falam a nossa língua e na realidade só falam a linguinha deles. Está satisfeita?

- Agora, sim. - disse Emília muito ganjenta com o triunfo. Conte outra.

(LOBATO, M. Fábulas, 2012, p. 12-14)

Portanto, além de preocupar-se em oferecer estratégias de contadiscursividade ao discurso colonial da fábula A cigarra e a formiga, de La Fontaine, de vesti-la à nacional e de reescrevê-la em prosa, Lobato (2012) preocupa-se, também, com seus aspectos formais. Ou seja, o autor brasileiro relaciona o que é narrado na fábula e a maneira com que ela é narrada.

No que respeita às estratégias de contradiscursividade, o mapeamento do discurso dominante da fábula de La Fontaine, que traz representações culturais do individualismo econômico, da visão materialista do mundo e da ética do trabalho, aparece no texto II A cigarra má.

Jean de La Fontaine, que viveu no século XVII, era filho de um pequeno burguês. Suas histórias se referem a um passado imemorial (quando os bichos falavam) e a um passado histórico (as fábulas de fabulistas gregos e romanos) e, ao mesmo tempo, eram dirigidas aos homens de sua época. Homens que viverem num século marcado pela ascensão da burguesia e consequente perda de poder da aristocracia. O processo iniciouse no século XV com a expansão do Mercantilismo e com as Grandes Navegações ${ }^{x}$ e teve como ápice a Revolução Industrial e a Revolução Francesa ${ }^{\mathrm{xi}}$.

A fábula A cigarra e a formiga, do poeta francês é (re)escrita, então, nesse momento social e histórico do século XVII. Logo, as representações culturais da burguesia atravessam o seu discurso ${ }^{\text {xii. }}$ 


\section{A Cigarra e a Formiga}

Tendo a Cigarra cantado

Durante todo o verão,

Viu-se ao chegar o inverno

Sem nenhuma provisão.

Foi á casa da Formiga,

Sua vizinha, e então

Lhe disse: - Querida amiga,

Podia emprestar-me um grão

Que seja, de arroz,

De farinha ou de feijão?

Estou morrendo de fome.

- Faz tempo então que não come? -

Lhe perguntou a Formiga,

Avara de profissão.

- Faz.

- E o que fez a senhora,

durante todo o verão?

- Eu cantei - disse a Cigarra.

- Cantou, é? Pois dança, agora!

(FONTAINE, L, 1997, p. 10, tradução de Ferreira Gullar)

A leitura e exposição das premissas subjacentes desse discurso dominante, que é outra estratégia de contradiscursividade, em conformidade com Tiffin (1987), é utilizada por Lobato (2012) no texto I A formiga boa, nos nove parágrafos iniciais.

Ao reentrar no texto de La Fontaine, o autor brasileiro expõe o discurso colonial burguês com suas representações culturais do individualismo econômico - "Aparece uma formiga friorenta, embrulhada num xalinho de paina. - Que quer? - perguntou, examinando a triste mendiga suja de lama e a tossir." (LOBATO, 2012, p. 12) -, da visão materialista do mundo - "E o que fez durante o bom tempo, que não construiu sua casa?" (LOBATO, 2012, p. 12) - e da ética do trabalho - "Ah!... exclamou a formiga 
recordando-se. Era você então quem cantava nessa árvore enquanto nós labutávamos para encher as tulhas?" (LOBATO, 2012, p. 12) - e, com isso, desestabiliza-o.

Essas representações culturais do discurso colonial burguês constroem os sujeitos do discurso - cigarra e formiga - dentro de um aparato de poder (FOUCAULT, 1995). Os sistemas de diferenciações - observar/abastecer, bom tempo/ [tempo de] chuvas, nas tocas/sem abrigo, embrulhada/tremendo, cantava/labutávamos - objetivam, segundo Foucault (1995), tanto a cigarra quanto as formigas, dividindo-as interiormente e em relação aos outros. Para o filósofo, esses sistemas de diferenciações são, ao mesmo tempo, condições e efeitos de relações de poder. Desse modo, o poder, na visão foucaultiana, integra as construções das identidades das personagens cigarra e formiga.

Bhabha (1998) ressalta, conforme mencionado anteriormente, que esse poder contém um saber retido e fetichista, que circula como uma forma limitada de alteridade denominada estereótipo. Desse modo, o estereótipo “é uma forma particular 'fixada' do sujeito colonial que facilita as relações coloniais e estabelece uma forma discursiva de oposição racial e cultural em termos da qual é exercido o poder colonial" (BHABHA, 1998, p. 121).

No texto I, A formiga boa, Lobato (2012) também faz uso de outra estratégia de contadiscursividade, que é a desconexão dos pressupostos do discurso colonial da fábula de La Fontaine, do ponto de vista transcultural ${ }^{\text {xiii }}$ de um colonizado brasileiro:

- Pois entre, amiguinha! Nunca poderemos esquecer as boas horas que sua cantoria nos proporcionou. Aquele chiado nos distraía e aliviava o trabalho. Dizíamos sempre: que felicidade ter como vizinha tão gentil cantora! Entre, amiga, que aqui terá cama e mesa durante todo o mau tempo.

A cigarra entrou, sarou da tosse e voltou a ser a alegre cantora dos dias de sol (LOBATO, 2012, p. 17). 
O discurso de Lobato (2012) corre "contra", então, o discurso colonial francês. Portanto, o discurso de Lobato é contrário ao modo de representação da alteridade denominada estereótipo na fábula A cigarra e a formiga, de La Fontaine e, consequentemente, de Esopo. Com isso, o autor brasileiro promove uma tradução (BHABHA, 1988), isto é, uma transformação de valores coloniais.

\section{Conclusão}

Monteiro Lobato foi um homem à frente de seu tempo. Empunhou inúmeras bandeiras nacionalistas, através das quais vestiu as fábulas europeias à brasileira. $\mathrm{O}$ autor percebeu, então, que no início do século XX a literatura brasileira destinada à infância era ainda dependente da europeia, pois grande parte dos livros vinha da França, quando em língua estrangeira, e de Portugal, quando em língua portuguesa, conforme expõe Arroyo (2011).

A dependência da literatura brasileira destinada à infância da literatura europeia decorreu da colonização portuguesa, que impôs seus padrões conteudísticos e ideológicos a essa criação. Lobato (2012) resistiu a essa literatura e subverteu seus padrões éticos e estéticos. Portanto, o autor brasileiro efetuou uma resistência discursiva:

uma 'resistência' que se manifesta como recusa a ser absorvida, uma resistência que envolve o que é resistido de maneira diferente, tomando o leque de influências exercidas pelo poder dominante, e alterando-as em ferramentas para expressar um senso profundamente arraigado de identidade e cultura (ASHCROFT, 1991, p. 20) ${ }^{\text {xiv }}$. 
Mas a produção contradiscursiva de Lobato (2012), que é uma resistência ao discurso colonial, é também o sinal de sua agência - "um olhar de duas vias, a dupla orientação, a capacidade de apropriação da tecnologia colonial sem ser absorvida por ela - o que perturba o ímpeto monológico do processo de colonização" (ASHCROFT, 1991, p.23) ${ }^{\mathrm{xv}}$. Logo, no processo de transformação da fábula A cigarra e a formiga, de La Fontaine, Lobato (2012) a 'usou' e 'resistiu' a ela ao mesmo tempo.

A fábula europeia encerra uma moral implícita (ou um discurso dominante implícito), por meio de uma estrutura dramática protagonizada pelos animais cigarra e formiga, cujos comportamentos deixam transparecer uma alusão aos seres humanos do século XVII, mas se apresenta, ainda no século XXI, como 'natural', universal e atemporal. Para Bagno (2006), esse caráter universal e atemporal se deve, sem dúvida, à sua ligação muito íntima com a sabedoria popular. Entretanto, em virtude de o discurso ser uma prática descontínua que pode ser ignorada ou excluída (FOUCAULT, 1996), a fábula europeia expôs-se à resistência e à contradição de Lobato (2012).

Desse modo, o contradiscurso do autor brasileiro funcionou dentro do discurso da fábula francesa em si. Em outras palavras, o texto literário canônico foi "consumido" por Lobato (2012) de tal maneira que se tornou a base para uma versão resistente e apropriada para as crianças brasileiras, com os valores e as suposições coloniais sutilmente subvertidos.

O contradiscurso, segundo Ashcroft (1991), é uma demonstração muito clara da ligação entre resistência e transformação, pois a sua emergência faz com que a centralidade ou a 'grandeza' do texto canônico não mais domine, com sua revelação da 'condição humana universal'. Passam a dominar, então, os novos horizontes culturais 
revelados dos autores pós-coloniais ou pertencentes a grupos marginalizados do Norte Global.

Entretanto, a resistência da contradiscursividade é totalmente eficaz apenas quando transforma a visão de possibilidades culturais do 'colonizado' (ou do marginalizado), esclarece Ashcroft (1991). Lobato (2012), a meu ver, efetua essa transformação.

\section{Referências}

ARROYO, L. Literatura infantil brasileira. São Paulo: Editora Unesp, 2011.

ASHCROFT, B. Post-colonial transformation. London: Routledge, 2001.

; GRIFFITHS, G; TIFFIN, H. The empire writes back: theory and practice in postcolonial literatures. 2. ed, London and New York: Routledge, 2002.

BHABHA, H. O local da cultura. Belo Horizonte: UFMG, 1998.

BAGNO, M. Fábulas fabulosas. In: CARVALHO, M, A, F, de; MENDONÇA, R, H. (orgs.). Práticas de Leitura e Escrita. Brasília: Ministério da Educação, 2006. p. 51-53. Disponível em: <http://files.brejodigital.webnode.com/200000056b7398b833c/livro_salto_praticas_de_leitura_e_escrita.pdf\#page=51>. Acesso em: 1 o jul. 2018.

BAKHTIN, M. O discurso no romance. In: Questões de literatura e de estética: a teoria do romance. São Paulo: Hucitec, p. 71-210, 2002.

FONTAINE, L. A cigarra e as formigas. In: Fábulas de La Fontaine. Tradução Ferreira Gullar. Rio de Janeiro: Revan, 1997. p. 10.

FOUCAULT, M. O sujeito e o poder. In: DREYFUS, H, L; RABINOW, P. Michel Foucault, uma trajetória filosófica (para além do estruturalismo e da hermenêutica). Tradução Vera Porto Carrero. Rio de Janeiro: Forense Universitária, 1995. p. 231- 249.

A ordem do discurso. São Paulo: Loyola, 1996.

LOBATO, M. A barca de Gleyre. São Paulo: Brasiliense, 1972. 
SANTOS, B. S; MENESES, M. P. (orgs.). Epistemologias do Sul. São Paulo: Cortez. 2010.

SOUZA, L. M. T. M. de. De versões mutantes e lama no ventilador: a questão da história na literatura pós-colonial. Cadernos de Estudos Linguísticos, Campinas, SP (30): 43-55, jan./jun. 1996.

TIFFIN, H. Post-colonial literatures and counter-discourse. Kunapipi, Austrália, v. 9, p. 1734, 1987.

Recebido em 23 de fevereiro de 2019.

Aceite em 4 de abril de 2019.

\footnotetext{
${ }^{\text {i }}$ Segundo Arroyo (2011), durante mais de 40 anos, os escritores Monteiro Lobato (1882-1948) e Godofredo Rangel (1884-1951), que foram amigos da vida inteira e mantiveram uma intensa correspondência, que se iniciou em 1903.

ii No sentido da representação do centro imperial ser contraditória e essencialmente etnocêntrica.

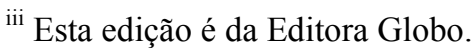

iv No original: "counterdiscursive strategies involve a mapping of the dominant discourse, a reading and exposing of its underlying assumptions, and the dis/mantling of these assumptions from the cross-cultural standpoint of the imperially subjectified 'local '(TIFFIN, 1987, p. 23, tradução minha).

v Epistemologias que contestam a Epistemologia do Norte, que eliminou da reflexão epistemológica o contexto cultural e político da produção e reprodução do conhecimento, segundo Santos e Meneses (2010).

${ }^{\text {vi }}$ No original: "they emerged in their present form out of the experience of colonization and asserted themselves by foregrounding the tension with the imperial power, and by emphasizing their differences from the assumptions of the imperial centre" (ASHCROFT; GRIFFITHS; TIFFIN, 2002, p. 2, tradução minha).

vii No original: "are thus constituted in counter-discursive rather than homologous practices, and they offer Tields of counter-discursive strategies to the dominant discourse" (TIFFIN, 1987, p.18, tradução minha).

viii Ainda no início do século XX as crianças brasileiras liam, basicamente, as fábulas traduzidas desse poetafabulista (ARROYO, 2011).

${ }^{\text {ix }}$ Nesse sentido, “a linguagem não é um meio neutro que se torne fácil e livremente a propriedade intencional do falante, ela está povoada e superpovoada de intenções de outem” (BAKHTIN, 2002, p. 100).

${ }^{\mathrm{x}}$ Para o aprofundamento do tema sugiro o link: http://persitenciadamemoria.blogspot.com/2007/09/

/mercantilismo-e-expanso-martima.html. Consultado em 07 de julho de 2018.

${ }^{x i}$ Para o aprofundamento do tema sugiro o link: https://caminhodasletras.wordpress.com/2011/02/14/ revolucao-industrial-francesa-e-o-capitalismo/ Consultado em 07 de julho de 2018.

xii "O discurso é um fenômeno social” (BAKHTIN, 2002, p. 71).
} 
xiii O ponto de vista de Lobato (2012) é transcultural porque a cultura brasileira foi transformada na junção com a cultura do colonizador português, de acordo com a explicação de Ashcroft (1991) para a transculturalidade.

xiv No original: a 'resistance' that manifests itself as a refusal to be absorbed, a resistance which engages that which is resisted in a different way, taking the array of influences exerted by the dominating power, and altering them into tools for expressing a deeply held sense of identity and cultural being (ASHCROFT , 1991, p. 20, tradução minha).

${ }^{\mathrm{xv}}$ No original: "A two-way look, dual orientation, the appropriation capacity of colonial technology without being absorbed by it - which disturbs the monological impetus of the colonization process"(ASHCROFT, 1991, p. 23, tradução minha). 